\title{
Aplicação da Logística Reversa: Estudo comparativo entre empresas de diferentes segmentos de um município do Estado do Paraná.
}

\author{
Cláudio Luiz CHIUSOLI \\ Universidade Estadual do Centro-Oeste (UNICENTRO), Guarapuava, PR, Brasil \\ Josiane POCZYNEK \\ Universidade Estadual do Centro-Oeste (UNICENTRO), Guarapuava, PR, Brasil \\ Silvio Roberto STEFANO \\ Universidade Estadual do Centro-Oeste (UNICENTRO), Guarapuava, PR, Brasil
}

Received 21 August 20; Accepted 24 November 20.

Evaluation System: Double Blind Review

Editor: Jose Lindenberg Julião Xavier Filho, Dr. ISSN: 2594-8040

To cite this paper: Chiusoli, C. L., Pocznek, J., \& Stefano, S. R. (2020). Aplicação da logística rever: Estudo comparativo entre empresas de diferentes segmentos de um município do Estado do Paraná. Journal of Perspectives in Management - JPM, 4, p. 101-112.

\begin{abstract}
Resumo
O estudo tem como objetivo analisar a aplicação da logística reversa de três empresas de diferentes ramos de atuação, levando em consideração as principais dificuldades e o destino dado aos materiais reciclados. Para tanto, foi adotada uma pesquisa classificada como exploratória, de caráter qualitativo, e aplicado um roteiro composto por perguntas abertas, caracterizando um estudo de caso. Por meio da pesquisa, foi possível identificar que as dificuldades que as organizações se deparam são especialmente devido à falta de incentivos municipais, conscientização e sensibilização da comunidade em geral. Dentre os principais achados, verificou-se a importância da reciclagem por meio da logística reversa, uma vez que destinam seus materiais para a produção de uma gama variada de itens, como telhas ecológicas, conduítes corrugados, cordas, vergalhões de aço, madeira plástica, embalagens para óleo lubrificante, dutos corrugados, luvas para emenda, além de substituir produtos como a pedra brita na construção civil.
\end{abstract}

Palavras-Chave: Logística Reversa; Sustentabilidade; Reciclagem. 


\section{Introdução}

A globalização da economia e a competição de mercado fazem com que as empresas busquem um diferencial competitivo, oferecendo uma melhor qualidade na prestação de serviços, a fim de atender às exigências da demanda dos consumidores; entretanto, isso tem contribuído para o aumento descontrolado do consumo, ocasionando grandes danos ao meio ambiente (Batista, Melo, \& Carvalho, 2016).

O homem, desde a sua existência, utiliza-se de recursos naturais para garantir a sobrevivência no ambiente. A partir disso, iniciou-se o processo de degradação da natureza, reflexo causado pelo aumento acelerado do consumo e demanda dos produtos. Nesse sentido, considera-se que a produção aumentou como consequência das demandas por produtos, e assim, havia descarte de resíduos de forma pouco planejada, gerando problemas ambientais (Musa, Ratzlaff, \& Gloeden, 2019).

Diante desse cenário, as empresas passaram a adotar cada vez mais práticas sustentáveis, de modo a contribuir com o meio ambiente e com a sociedade, além de obter diferencial competitivo em relação aos concorrentes. Nesse sentido, investem na comercialização de produtos oriundos de matérias-primas biodegradáveis, evitando o desperdício e buscando parceiros com mesmos princípios organizacionais (Sousa \& Novais, 2017).

Cabe ainda ressaltar que há muito material com descarte incorreto, o que afeta a vida útil de aterros sanitários, os quais impactam consideravelmente a natureza. Tudo isso é reflexo da falta de orientação e sensibilização da comunidade para as práticas da reciclagem; e sobretudo, da falta de políticas que valorizam o trabalho dos agentes ecológicos e das empresas que contribuem para a reciclagem dos produtos que são nocivos para o meio ambiente. Essas empresas e agentes cumprem papel importantíssimo na cadeia da reciclagem, principalmente em cidades em que o índice de desenvolvimento humano (IDH) é considerado alto, com 0,731 (em uma escala de 0 a 1), como é o caso da cidade onde estão instaladas as empresas estudadas (Ipardes, 2020).

Neste contexto, muito se tem falado sobre logística reversa; esta temática tem, cada vez mais, se inserido no contexto empresarial. De acordo com Pereira (2010), a logística reversa pode ser compreendida como o processo de planejamento, implementação e controle de fluxos de matérias-primas, de produtos em processo e acabados, e de informações, desde o consumidor final até o fornecedor, com a proposta de recuperar valor ou fazer uma apropriada disposição ambiental.

Desta forma, pode-se compreender que logística reversa é, de acordo com Santos, Oliveira e Pimentel (2019), fazer com que os produtos possuam um ciclo de vida ininterrupto. Para tanto, a importância do presente estudo se justifica pelos benefícios e importância que a logística possui, tanto para as organizações quanto para o meio ambiente e a sociedade.

Assim, exposta a justificativa do estudo, no que diz respeito aos benefícios empresariais, entende-se que a logística reversa seja importante, pois contribui para a redução de custos na produção, devido à possibilidade de reutilização e remanufatura dos materiais; e no que tange aos benefícios sociais e ambientais, possibilita a minimização de gastos para a manutenção de aterros sanitários e transporte dos resíduos, além da redução da poluição das águas e solo.

Assim, a problemática da pesquisa se resume da seguinte forma: como as empresas dos três ramos investigados adotam como política organizacional a implantação da logística reversa, bem como quais são as suas dificuldades de implementação e qual o destino dado aos materiais reciclados?

Para tanto, o objetivo do estudo é analisar a aplicação da logística reversa de três empresas de diferentes ramos de atuação, levando em consideração as principais dificuldades e o destino dado aos materiais reciclados.

Como objetivos específicos, têm-se: i) identificar a caracterização das empresas investigadas; ii) levantar a principal matéria-prima utilizada na produção; iii) verificar como se dá a forma de processamento do material utilizado; iv) levantar qual a quantidade de toneladas diárias recebidas para produção; v) verificar como é a forma de reaproveitamento/descarte do produto que sobra; vi) 
levantar se há existência de incentivos municipais no que diz respeito à logística reversa; e vii) levantar as principais dificuldades encontradas pela empresa

O presente artigo foi estruturado inicialmente pela introdução, seguindo com a apresentação dos conceitos teóricos; na sequência, apresenta os procedimentos metodológicos adotados para realizar a pesquisa. A seção seguinte refere-se às análises dos dados coletados e discriminação dos resultados obtidos, por fim, apresenta as considerações finais do estudo.

\section{Referencial Teórico}

Foi realizada uma revisão teórica, visando fundamentar o assunto e os principais aspectos de logística reversa. A logística reversa possui como objetivo principal a gestão e distribuição de materiais descartáveis ao destino correto, de forma que contribua para o retorno ao processo produtivo, transformando-se em novos produtos, beneficiando o meio ambiente e a sociedade, e agregando valor econômico.

Dentro do processo de logística, existem algumas etapas no ciclo, sendo: coleta, inspeção, separação dos materiais, compra/venda e processamento (Oliveira \& Silva, 2011).

O Ministério do Meio Ambiente (2017) define a logística reversa como um instrumento de desenvolvimento econômico e social, caracterizado por um conjunto de ações, procedimentos e meios destinados a viabilizar a coleta e a restituição dos resíduos sólidos ao setor empresarial, para reaproveitamento, em seu ciclo ou em outros ciclos produtivos, ou outra destinação final ambientalmente adequada.

Além disso, segundo Wille e Born (2012), a logística se divide em duas áreas: de pósconsumo e de pós-venda. De acordo com os autores, a logística de pós-consumo possui como responsabilidade o fluxo de informações referente aos bens que necessitam retornar à cadeia produtiva para serem reaproveitados, reutilizados ou descartados de forma correta.

Já, no que tange à logística de pós-venda, esta possui como responsabilidade o fluxo de informações de retorno dos bens à cadeia devido a defeitos na fabricação ou funcionamento, excesso de mercadorias, término da validade, ou itens que necessitam de consertos (Silva, Rolin, Maranhã, \& Gonçalves, 2017; Wille \& Born, 2012).

Fatores econômicos, legislativos, bem como ecológicos estão entre as razões que levam as empresas a adotarem a logística reversa; sendo que as principais razões de cunho econômico são o reaproveitamento de matéria-prima nas indústrias, reuso e remanufatura (Silva \& Pimentel, 2019).

Referente ao aspecto legislativo, as normas e leis estão cada vez mais severas, reflexo da preocupação com o descarte e destino correto de materiais, para não acarretar o pagamento de multas. No que diz respeito ao aspecto ecológico, as empresas se sensibilizaram e abriram as portas para a promoção da preservação ambiental, alcançando inúmeros benefícios, além do reaproveitamento de recursos, reduções de custos, e o ganho de imagem perante os clientes, visto que a conscientização ecológica dos consumidores gera uma pressão para que as empresas reduzam os impactos negativos de sua atividade no meio ambiente (Camargo \& Souza, 2005).

Importante frisar que as legislações ambientais caminham no sentido de tornar as empresas cada vez mais responsáveis por todo o ciclo de vida dos produtos, o que significa que o fabricante é responsável pelo destino do material após a entrega aos clientes e pelo impacto ambiental provocado pelos resíduos gerados em todo o processo produtivo, e também após o consumo.

O Ministério do Meio Ambiente (2017) cita que, entre outros princípios e instrumentos introduzidos pela Política Nacional de Resíduos Sólidos (PNRS), a Lei $\mathrm{n}^{\mathrm{o}} 12.305$, de 2 de agosto de 2010, e seu regulamento, Decreto $\mathrm{N}^{\circ} 7.404$ de 23 de dezembro de 2010, destacam a responsabilidade compartilhada pelo ciclo de vida dos produtos e a logística reversa. Nos termos da PNRS, a responsabilidade compartilhada pelo ciclo de vida dos produtos é o conjunto de atribuições individualizadas e encadeadas dos fabricantes, importadores, distribuidores e comerciantes, dos consumidores e dos titulares dos serviços públicos de limpeza urbana e de manejo dos resíduos sólidos, para minimizar o volume de resíduos sólidos e rejeitos gerados, bem como para reduzir os impactos causados à saúde humana e à qualidade ambiental decorrentes do ciclo de vida dos produtos, nos termos desta Lei. 
Desse modo, há uma busca constante pela sustentabilidade e responsabilidade socioambiental, aspectos que passaram a ser inseridos no planejamento das empresas e, quando bem aplicados, proporcionam a redução de custos diretos na produção, em consequência da diminuição do desperdício de matérias-primas, permitindo a reutilização de recursos, economia de água e energia (Bernardes, Freitas, \& Pfitscher, 2017), bem como a redução de custos representados por multas e/ou indenizações provindas de danos causados ao meio ambiente, ou à saúde da população que tenha residências, creches ou hospitais nas proximidades das unidades de produção da empresa e/ou indústria (Ribeiro, Costa Silva, \& Lopes Filho, 2019).

Vale ressaltar ainda que a logística reversa (LR) pode ser implantada em qualquer tipo de empresa, independentemente do ramo de atuação, tendo em vista que o ramo de reciclagem está em crescimento constante. Isso pode ser reforçado através de uma pesquisa realizada pelo Sistema Nacional de Informações Florestais (2018), que aponta que o Brasil figura entre os maiores recicladores de papéis do mundo, recuperando cerca de $60 \%$ daquilo que é consumido internamente; e o mercado de reciclagem geral do País movimenta hoje cerca de $\mathrm{R} \$ 3$ bilhões, com potencial para gerar valores muito maiores ao longo do tempo (Compromisso Empresarial para Reciclagem, 2018).

\section{Procedimentos Metodológicos}

Neste estudo foi adotada uma abordagem qualitativa classificada como descritiva, qual, segundo Gerhardt e Silveira (2009), não se preocupa com representatividade numérica, mas sim com o aprofundamento da compreensão de um grupo social ou de uma organização.

Para isso, foi realizado levantamento de informações em artigos de revista, livros acadêmicos, material eletrônico e nos sites das empresas participantes, caracterizando uma pesquisa bibliográfica, a qual, de acordo com Rampazzo (2005), tem a finalidade de ampliar o conhecimento na área, dominá-lo, para depois utilizá-lo como modelo teórico que dará sustentação a outros problemas de pesquisa.

Dessa forma, dando sequência ao estudo, foi realizada uma coleta de dados com três empresas de diferentes ramos de atuação no município, caracterizando um estudo de caso múltiplo. No que se refere ao estudo de caso, este é considerado como o método que possui o intuito de compreender fenômenos sociais de forma mais complexa, preservando as características e significâncias dos eventos da vida real (Silva \& Menezes, 2005).

Yin (2015) complementa que o estudo de caso múltiplo se trata de uma metodologia que abrange planejamento, técnicas de coletas de dados e análise, e utiliza-se de mais de uma fonte de informação, como: documentos, registros, entrevistas, observação direta.

Nesse sentido, foram estudados documentos e registros no site das empresas participantes, realizado entrevistas com gestores e feita observação direta, "in loco", nas empresas quando visitadas para abordagem da pesquisa.

Assim, segundo Gil (2002), a utilização de múltiplos casos proporciona evidências inseridas em diferentes contextos. Por outro lado, uma pesquisa com múltiplos casos requer uma metodologia mais apurada e mais tempo para coleta e análise dos dados, visto que é necessário reaplicar as mesmas questões em todos os casos.

Para tanto, as empresas selecionadas para o estudo trabalham em ramos diferentes e com matéria-prima principal distintas, sendo: embalagem de defensivos agrícolas, caixas longa vida e isopor. A abordagem foi realizada pessoalmente, por meio de agendamento com o responsável pela organização, mediante utilização de um roteiro não estruturado, composto por sete perguntas abertas, visando atender o objetivo do estudo.

Resumidamente, o roteiro tratava sobre a caracterização da empresa, principal matéria-prima utilizada, forma de processamento do material, quantidade de toneladas recebida diariamente para produção, forma de reaproveitamento dos materiais descartados, existência de incentivos municipais, e quais as principais dificuldades encontradas pelas empresas. 
Por fim, a análise dos dados consistiu na técnica de análise de conteúdo, a qual baseia-se em textos e na transcrição realizada no processo de pesquisa quando realizadas a entrevista junto aos gestores (Puglisi \& Franco, 2005). No decorrer do trabalho, as empresas são mencionadas como Empresa A (defensivos agrícolas), Empresa B (caixas longa vida), Empresa C (isopor), de forma que mantenha o anonimato das organizações estudadas.

\section{Discussão dos Resultados}

Para as entrevistas, os responsáveis pelas informações foram os diretores executivos das empresas, os quais auxiliaram para o desenvolvimento do estudo. A seguir são apresentadas as empresas, bem como as atividades que elas desenvolvem, levantando as dificuldades da aplicação da logística reversa em seus estabelecimentos, conforme os objetivos propostos.

\subsection{Análise dos Resultados da empresa A (Defensivos Agrícolas)}

A empresa "A" foi fundada no ano de 2003, de iniciativa privada e não familiar, conta com a colaboração de 8 funcionários, a principal e única matéria-prima que chega diariamente no local são embalagens de defensivos químicos utilizados na agricultura para combater e prevenir pragas nas lavouras.

Diariamente, a empresa recebe em torno de 7 a 9 toneladas de embalagens; o material é entregue na unidade pelos próprios consumidores, ressaltando ainda a Lei 9.974/2000 e Decreto 4.074/2002, onde impõem explicitamente que as embalagens de produtos agroquímicos, posteriormente a sua utilização, devem ser devolvidas em associações regulamentadas, dentro do prazo de um ano a partir da data da compra do defensivo, tratando esta atitude não apenas como conscientização ambiental, mas como uma forma de manter-se regularizado com a lei.

Antes de encaminhar as embalagens para a unidade de recolhimento, os agricultores precisam realizar a tríplice lavagem: assim que os frascos estiverem vazios por completo, deve ser adicionado o equivalente a um quarto do tamanho da embalagem de água limpa, a fim de retirar todos os resíduos do produto. A mesma operação é repetida três vezes. Além do mais, o procedimento deve ser realizado utilizando equipamentos de segurança, como óculos, máscara e luvas. Após a tríplice lavagem, as embalagens devem ser inutilizadas e danificadas, para que não haja possibilidade de servir como recipientes para outros produtos; para isso, são feitos cortes e furos nas laterais e no fundo dos frascos. Após este processo, são encaminhadas para a associação que recolhe o material.

$\mathrm{Na}$ associação, as embalagens são verificadas e separadas, uma a uma; os frascos são separados de acordo com critérios de embalagens que podem e não podem ser lavadas. As embalagens laváveis (frascos de plástico, vidro ou lata) seguem para a reciclagem, enquanto as embalagens não laváveis (caixas de papelão, saquinhos plásticos contaminados) partem para a incineração.

Após separação, os fracos que seguiram para a reciclagem são prensados e mantidos em local seco e fresco até o destino correto. Tais materiais permanecem na associação por um prazo de 30 dias até a entrega, sendo que as empresas que recolhem os fardos localizam-se no Estado de São Paulo, e outra na cidade de Maringá.

Após recolhimento das embalagens prensadas, o destino é a produção de: conduítes corrugados, cordas, vergalhões de aço, madeira plástica, embalagens para óleo lubrificante, dutos corrugados, luvas para emenda, economizadores de concreto, barricas de papelão, barricas plásticas, eletrotubos para telefonia, sacos plásticos para lixo hospitalar, tampas para embalagens de defensivos agrícolas. Todos estes produtos são confeccionados através de embalagens de defensivos agrícolas reciclados (Agrolink, 2008).

Embora haja leis e fiscalizações cada vez mais rígidas, o grande problema relatado no decorrer da pesquisa foi justamente a conscientização do pequeno produtor sobre a importância e obrigação de fazer a devolução das embalagens de agroquímicos na unidade recolhedora.

Por se tratar de pequenas propriedades, o consumo de defensivos é baixo, diante disso, para o agricultor se torna inviável o deslocamento para devolver apenas alguns litros do produto. Esta 
atitude é preocupante, pois, em muitos casos, estes frascos são reaproveitados para armazenar outros produtos, podendo prejudicar a saúde humana e animal, além de ocasionar a poluição de lençóis freáticos e solo quando o manejo é realizado de forma incorreta.

Nota-se a falta de incentivos por parte da prefeitura, bem como de outros órgãos que poderiam realizar campanhas de sensibilização, ou então disponibilizar caminhões para realizar a coleta das embalagens nas propriedades rurais; atitudes que proporcionariam inúmeros benefícios.

Dentro da condição analisada, é importante destacar que a cadeia produtiva de defensivos agrícolas é exemplo mundial na implementação da logística reversa e é utilizada como benchmarking para outras cadeias abrangidas na Lei 12.305, art. 33, cujos segmentos citados estão obrigados a efetuar a logística reversa (Barbosa, et al. 2017).

Reitera-se então que a dificuldade principal da empresa "A" é que, apesar das normas e legislações punirem com multas os produtores que não devolvem as embalagens, os pequenos agricultores são os causadores de maior impasse quando o assunto é conscientização. Como adquirem agrotóxicos em pequena quantidade, eles não possuem preocupação em devolver as embalagens ao local correto e, até mesmo, as reutilizam para guardar pregos, parafusos, óleo, entre outros, o que pode ser prejudicial à saúde quando o manejo é feito de forma incorreta.

\subsection{Análise dos Resultados da empresa B (Caixas de Longa Vida)}

A empresa "B" foi fundada no ano de 2012 , de iniciativa privada e não familiar, possui também outra unidade em São Paulo, a qual iniciou suas atividades no final do ano de 2018.

Dentro da empresa, a principal e única matéria-prima utilizada no processo produtivo é a embalagem longa vida, como: caixa de leite, creme de leite, leite condensado, suco, água de coco, entre outras, que são compradas diretamente de cooperativas e associações de todo o Brasil, inclusive da associação de catadores da cidade.

O início de todo o processo ocorre através da coleta desses materiais nas residências por meio dos agentes ecológicos; posteriormente, o material é entregue à associação de catadores, que recicla e prensa as caixas, e as vende para a empresa "B".

Desde o ano de 2012, a empresa compra apenas $1 \%$ do material que é produzido na própria cidade, o restante vem de outras cidades e regiões; em média, a empresa recebe diariamente 30 toneladas do produto.

No entanto, um dado que chama a atenção e causa dificuldade para a empresa é que o município possui em torno de 180 mil habitantes, com isso a cidade tem potencial de geração de lixo muito maior; porém, a porcentagem que a recicladora compra de material da cidade é pequena, apenas $1 \%$. O que evidencia a falta de incentivo dos representantes públicos e sensibilização da população para um ato simples e fácil como a reciclagem. Isso pode ser comprovado na medida em que o aterro sanitário, que foi planejado e desenvolvido para ter vida útil até o ano de 2021, está com cerca de $80 \%$ da capacidade preenchida.

Logo que o material chega até a empresa "B", as embalagens são encaminhadas para a máquina "hidrapulper" e é acrescentado água, sem uso de qualquer tipo de produto químico. O material fica em agitação por aproximadamente 30 minutos até que as fibras se desmanchem. De um lado da máquina sai a massa com papel das caixas longa vida, e de outro sai a mistura de plástico e alumínio.

Do papel extraído das caixas são confeccionadas mantas de celulose reciclada; esse material é vendido para as fábricas que produzem caixas de sapato, capa de cadernos, sacos de cimento, caixas de ovos, entre outros, sendo empresas fora do município. O plástico e o alumínio retirados das caixas longa vida são prensados e vendidos para uma fábrica instalada na própria cidade, a qual produz telhas ecológicas, que são resistentes, impermeáveis, térmicas, acústicas e leves.

Vale ressaltar que as embalagens longa vida são compostas de $75 \%$ de papel, $20 \%$ de plástico e 5\% alumínio, o que leva em torno de 100 anos para se decompor na natureza (Almeida Santos, et al, 2017). 
Assim, a dificuldade, além das questões da gestão municipal, está na sensibilização da comunidade para reciclagem das embalagens longa vida.

\subsection{Análise dos Resultados da empresa C (Isopor)}

A empresa "C" foi fundada no ano de 2016, de iniciativa privada e familiar, conta com a colaboração de 4 funcionários. A principal matéria-prima utilizada pela empresa é o poliestireno, conhecido popularmente como isopor ou EPS.

$\mathrm{Na}$ empresa, são fabricadas molduras internas, externas e rebaixo, chapas e placas em geral, vista de portas e janelas, embalagens, letras, bolo fake, lajes, forros, revestimento de paredes e colunas, telhas de EPS etc.

Os blocos de isopor para confecção dos produtos são adquiridos na cidade de Curitiba; a empresa "C" ainda não possui fábrica própria para produzir a matéria-prima, mas há projeto em estudo para logo implantá-la.

Cada bloco adquirido mede $2 \times 1$ metro, havendo os blocos de isopor fabricados com material virgem e reciclado. O isopor virgem é composto por $100 \%$ de material "puro", possui maior densidade, contudo se torna mais caro que o reciclado; o valor do $\mathrm{m}^{3}$ do isopor virgem é $\mathrm{R} \$ 180,00$. Já, o bloco de isopor reciclado é composto de $40 \%$ de material virgem e $60 \%$ de material reciclado, ou seja, são produzidos com materiais recolhidos no meio ambiente através de agentes ecológicos, lojas de eletrodomésticos, papelaria etc. $\mathrm{O}$ custo do $\mathrm{m}^{3}$ do isopor reciclado é de $\mathrm{R} \$ 170,00$.

Vale considerar que o isopor virgem é utilizado normalmente para fabricar as molduras internas e externas, chapas, forros, entre outros, devido a sua maior densidade comparado ao isopor reciclado. $\mathrm{O}$ isopor reciclável é utilizado pela empresa para atender papelarias que solicitam a confecção de caixas e molduras de isopor para proteger quadros, xícaras, porta-retrato etc.

Assim que chegam à empresa, os blocos são cortados conforme a necessidade de produção e também de acordo com a solicitação do cliente. Para cortes e desenhos do isopor, a máquina que a empresa possui é denominada Pantógrafo, onde a matéria-prima é cortada com fio quente; para cortes de chapas retas, a máquina utilizada é chamada de Tobogã.

Além disso, a empresa também possui um triturador, para o qual são encaminhados os resíduos produzidos, ou sobras inutilizáveis, os quais são transformados em flocos de isopor, que são ensacados em sacos de 300 litros e vendidos para construção civil ao preço de $\mathrm{R} \$ 32,00$ a sacaria.

Na construção civil, estes flocos gerados de sobras inutilizáveis do isopor substituem a pedra brita na concretagem, gerando economia, leveza à estrutura, sendo ainda um isolante térmico e acústico, garantindo baixa absorção de água. Também passa a substituir a madeira, pois o material pode ser utilizado para fazer rodapés, vista de portas e janelas com peças personalizadas e resistentes, alinhando rapidez na instalação e estética para o ambiente.

Além da construção civil, os flocos também são vendidos para outras empresas que utilizam o material para encher puffs, assentos, estofados, ursos de pelúcia, pescoceiras, almofadas etc. Vale ressaltar que todos os resíduos ou sobras produzidas dentro ou fora da empresa (residência do cliente) são recolhidos e transformados em flocos de isopor, nada é descartado de forma incorreta ou perdido.

No entanto, a dificuldade maior encontrada pela empresa é a falta de auxílio por parte da gestão municipal, bem como da população envolvida no descarte correto do material.

O isopor, ou poliestireno, é um material $100 \%$ reciclável. Derivado do petróleo, o produto na verdade é um plástico, podendo ser descartado como outros resíduos: papel, vidro, metal etc. De acordo com uma pesquisa realizada pela empresa de embalagens, o poliestireno, mais conhecido como isopor, é totalmente reciclável, mas apenas $7 \%$ dos brasileiros sabem disso (Meiwa embalagens, 2015).

Desta forma, por iniciativa própria da empresa, em horários vagos, funcionários passam a transitar pelo centro e bairros da cidade para recolher o material que encontram jogados pelas ruas, além de realizar acordos com lojas de eletrodomésticos e papelarias para armazenar os materiais para que, a cada semana, algum funcionário da empresa passe recolhendo. 
Ressaltando que, segundo dados da Plastivida Instituto Sócio-Ambiental dos Plásticos (2015), foram produzidos no Brasil cerca de 82,9 mil toneladas de poliestireno, sendo que apenas 7 mil toneladas $(8,4 \%)$ foram recicladas, número relativamente baixo e que gera grande preocupação, visto que o isopor possui tempo indeterminado para se degradar na natureza.

Nesse sentido, os benefícios financeiros e ambientais em relação aos materiais reciclados, bem como a criação de incentivos fiscais e mecanismos regulatórios poderiam auxiliar na alavancagem do negócio mencionado (Paschoalin Filho, Frasson, \& Conti, 2019).

Por fim, destaca-se então que, além dos entraves com a falta de incentivo da prefeitura, a empresa " $C$ " encontra dificuldades na falta de conscientização das pessoas para a reciclagem do isopor; poucos conhecem a existência da empresa que presta o serviço de reciclagem desse material, são os próprios empresários que recolhem nas lojas, papelarias ou nas ruas os isopores que estão sem utilidade, para transformá-los em flocos e dar-lhes o destino correto.

\subsection{Comparativo entre as empresas A, B e C}

A partir dos resultados obtidos, segue no Quadro 1 um resumo comparativo das entrevistas realizadas com os três gestores das empresas A, B e C.

\begin{tabular}{|c|c|c|c|}
\hline \multicolumn{4}{|c|}{ Quadro 1 - Comparativo das respostas entre as 3 empresas } \\
\hline VARIÁVEIS & EMPRESA A & EMPRESA B & EMPRESA C \\
\hline $\begin{array}{c}\text { Caracterização da empresa } \\
\text { investigada }\end{array}$ & $\begin{array}{l}\text { Empresa privada não } \\
\text { familiar. }\end{array}$ & $\begin{array}{l}\text { Empresa privada não } \\
\text { familiar. }\end{array}$ & $\begin{array}{l}\text { Empresa privada e } \\
\text { familiar. }\end{array}$ \\
\hline $\begin{array}{l}\text { Principal matéria-prima } \\
\text { utilizada na produção }\end{array}$ & $\begin{array}{c}\text { Embalagens de } \\
\text { defensivos agrícolas }\end{array}$ & Embalagens longa vida & Poliestireno (isopor) \\
\hline $\begin{array}{c}\text { Processamento do } \\
\text { material }\end{array}$ & $\begin{array}{c}\text { Separação das } \\
\text { embalagens laváveis das } \\
\text { não laváveis - Prensar. }\end{array}$ & $\begin{array}{l}\text { Agitação das embalagens } \\
\text { no hidrapulper para } \\
\text { separação do papel, } \\
\text { plástico e alumínio. }\end{array}$ & $\begin{array}{c}\text { Picagem do isopor } \\
\text { inutilizável para } \\
\text { transformação em flocos. }\end{array}$ \\
\hline $\begin{array}{c}\text { Quantidade de toneladas } \\
\text { diárias recebida para } \\
\text { produção }\end{array}$ & 7 a 9 toneladas diárias & 30 toneladas diárias & Não mensurado \\
\hline $\begin{array}{c}\text { Forma de } \\
\text { reaproveitamento dos } \\
\text { materiais descartados }\end{array}$ & $\begin{array}{c}\text { Produção de conduítes } \\
\text { corrugados, cordas, } \\
\text { vergalhões de aço, } \\
\text { embalagens para óleo } \\
\text { lubrificante, luvas para } \\
\text { emenda, economizadores } \\
\text { de concreto, eletrotubos } \\
\text { para telefonia, sacos } \\
\text { plásticos para lixo } \\
\text { hospitalar, tampas para } \\
\text { embalagens de } \\
\text { defensivos agrícolas. }\end{array}$ & $\begin{array}{l}\text { Confecção de caixas de } \\
\text { sapatos, ovos, capas de } \\
\text { cadernos, sacos de } \\
\text { cimento e telhas } \\
\text { ecológicas. }\end{array}$ & $\begin{array}{l}\text { Produção de flocos de } \\
\text { isopor os quais } \\
\text { substituem a pedra brita } \\
\text { na concretagem. } \\
\text { Enchimento de puffs, } \\
\text { assentos, estofados, ursos } \\
\text { de pelúcia, pescoceiras, } \\
\text { almofadas. }\end{array}$ \\
\hline $\begin{array}{c}\text { Existência de incentivos } \\
\text { municipais }\end{array}$ & $\begin{array}{l}\text { Não possui incentivos } \\
\text { por parte da prefeitura. }\end{array}$ & $\begin{array}{l}\text { Não possui incentivos } \\
\text { por parte da prefeitura. }\end{array}$ & $\begin{array}{l}\text { Não possui incentivos } \\
\text { por parte da prefeitura. }\end{array}$ \\
\hline $\begin{array}{c}\text { Principais dificuldades } \\
\text { pelas empresas }\end{array}$ & $\begin{array}{l}\text { Conscientização dos } \\
\text { agricultores para } \\
\text { devolução das } \\
\text { embalagens. }\end{array}$ & $\begin{array}{l}\text { Conscientização da } \\
\text { comunidade em geral } \\
\text { para reciclagem das } \\
\text { embalagens longa vida. }\end{array}$ & $\begin{array}{l}\text { Conscientização da } \\
\text { comunidade em geral } \\
\text { para necessidade da } \\
\text { reciclagem do isopor. }\end{array}$ \\
\hline
\end{tabular}

Fonte: elaborado pelos autores (2020).

Por fim, estes foram os exemplos da aplicabilidade da logística reversa em empresas de diferentes ramos de atuação, cada qual com seus impasses e compromisso com a responsabilidade socioambiental.

Em comum, de forma bastante destacada pelos gestores, verifica-se a ausência de incentivos municipais, uma vez que são empresas de segmentos distintos no processo de reciclagem. Por outro lado, provavelmente essa forma de incentivo deve ocorrer mais no âmbito estadual, pois há 
incentivos governamentais que, além de estimular a criação de empregos via situação tributária, contam com uma intervenção de estímulo direto em que o próprio estado demanda esses empregos (Pauli \& Greco, 2017). A seguir, apresenta-se as conclusões, contribuições e limitações do estudo.

\section{Considerações Finais}

Com este estudo foi possível atingir de forma satisfatória o objetivo, o qual foi analisar a aplicação da logística reversa em três empresas de diferentes ramos de atuação, levando em consideração as principais dificuldades e o destino dado aos materiais reciclados.

Entre os exemplos apresentados sobre a aplicação da logística reversa, destaca-se como aspectos em comum que as três empresas possuem quando o assunto é reutilização e destino correto dos produtos a pela falta de incentivo municipal e a falta de conscientização da população em geral.

Em resumo, tem-se que a empresa " $A$ " é responsável pela reciclagem de embalagens de agrotóxicos, o destino final dos materiais é a fabricação de cordas, vergalhões de aço, madeira plástica, dutos corrugados, luvas para emenda, economizadores de concreto etc.

A empresa "B", a qual recicla caixas longa vida, o destino principal é encaminhar o material para fabricação de telhas ecológicas em uma fábrica presente na cidade.

E, por fim, na empresa "C", que fabrica molduras com isopor, o destino das sobras e resíduos que as máquinas de corte geram é a venda para a construção civil, onde os flocos de isopor são utilizados para substituir a pedra brita na concretagem.

Importante destacar que os materiais produzidos pelas empresas $\mathrm{A}, \mathrm{B}$ e $\mathrm{C}$, quando transformados no produto final, partem para utilização na construção civil, em substituição a outros produtos, o que gera economia alinhada à estética, resistência e qualidade; reforçando, entre as várias indústrias que reaproveitam o material reciclado quanto ao seu destino, a importância que a construção civil, a qual gera inúmeros resíduos, tem no reaproveitamento dos materiais, utilizandose até mesmo da substituição de produtos nas construções, tornando-as sustentáveis.

Diante do exposto, é importante discutir esta realidade, inclusive demonstrar que tudo pode se transformar em algo novo, e que a reciclagem é algo simples e fácil de realizar; pois cada vez mais é possível ver indícios do prejuízo que o homem está provocando, que se refletem em diversas catástrofes ambientais, como destruições, alagamentos e outros.

Como contribuições do estudo, entende-se que esse debate leva a reflexão da sociedade em geral para o desenvolvimento sustentável, de forma que há uma convergência entre vários setores da sociedade sobre os impactos, consequências e a importância que tem a logística reversa. Da mesma forma, sensibilizar os gestores públicos de que é possível adotar políticas de logística reversa nas cidades, de forma a minimizar os impactos ambientas, gerar emprego e renda.

Como limitação da pesquisa tem-se que a análise está restrita somente as três empresas participantes no estudo de caso, e não cabe inferir que as dificuldades sejam iguais em outras regiões ou outros setores estudados.

Como estudos futuros, sugere-se investigar a percepção dos consumidores em relação a uma empresa que possui políticas e práticas sustentáveis e se realmente este aspecto contribui para a obtenção de imagem positiva. Da mesma forma, estender esse estudo a outros segmentos de atuação, diferentes das empresas participantes, que estão na cadeia da logística reversa.

\section{Referências}

Agrolink. (2008) Embalagens são transformadas em 15 materiais reciclados. 2008. Disponível em: https://www.agrolink.com.br/noticias/embalagens-sao-transformadas-em-15-materiaisreciclados_27593.html. Acesso em 04 de março de 2019.

Almeida Santos, T., Tamanaga, B., Rogick Athiê, A. A., \& Satoshi Miyamaru, E. (2017). Influência da granulometria do resíduo de embalagens Longa Vida na preparação de placas Drywall. InterfacEHS, 12(1).

Barbosa, N. D. et al. (2017). Logística reversa das embalagens de agrotóxicos: um olhar sobre a evolução da legislação até a lei 12.305/2010. Agropampa: Revista de Gestão do Agronegócio, v. 2, n. 1 . 
Batista, K. R., Melo, J. F. M., \& Carvalho, J. R. M. de. Evidenciação dos itens ambientais nas empresas do setor de mineração de metálicos cadastradas na BM\&FBOVESPA. Revista de Gestão Ambiental e Sustentabilidade - GeAS, v. 5, n. 1, 2016.

Bernardes, R., Freitas, C. L. de, \& Pfitscher, E. D. (2017). Análise de sustentabilidade ambiental: estudo multicaso em duas empresas do setor de engenharia com a aplicação parcial do sicogea geração 3. Caderno De Administração, 25(1), 47-63.

Camargo, I., \& Souza, A. E. (2005). Gestão dos resíduos sob a ótica da logística reversa. In: Encontro Nacional de Gestão Empresarial e Meio Ambiente. In: VIII ENGEMA - Encontro Nacional sobre Gestão Empresarial e Meio Ambiente, Rio de Janeiro.

Compromisso empresarial para reciclagem. (2017). Embalagens longa vida. Disponível em: http://cempre.org.br/artigo-publicacao/ficha-tecnica/id/9/embalagens-longa-vida. Acesso em: 21 de fevereiro 2019.

Gerhardt, T. E., \& Silveira, D. T. (2009). Métodos de pesquisa. (Organizadores) Coordenado pela Universidade Aberta do Brasil - UAB/UFRGS e pelo Curso de Graduação Tecnológica Planejamento e Gestão para o Desenvolvimento Rural da SEAD/UFRGS. Porto Alegre: Editora da UFRGS.

Gil, A. C. (2017). Como elaborar projetos de pesquisa. 4. ed. São Paulo: Atlas.

Meiwa embalagens. (2015). Sustentabilidade. Disponível em: http://www.meiwa.com.br/. Acesso em 02 de fevereiro de 2019.

Ipardes - instituto paranaense de desenvolvimento econômico e social (org.). (2020). Caderno estatístico. 2020. Disponível em: http://www.ipardes.gov.br/. Acesso em: 11 abr. 2020.

Ministério do meio ambiente. (2017). Logística Reversa. Disponível em: http://www.mma.gov.br/cidades-sustentaveis/residuos-perigosos/logistica-reversa. Acesso em: 15 de fevereiro 2019.

Musa, C. F. A., Ratzlaff, G., de Freitas, A. M., \& Gloeden, D. B. (2019). Análise social e ergonômica da atividade de coleta informal de material reciclável. Revista Tecnologia e Tendências, 10(1), 200-215.

Oliveira, A. A., \& Silva, J. T. M. (2011). A logística reversa no processo de revalorização dos bens manufaturados. REA-Revista Eletrônica de Administração, 4(2).

Pereira, S. A. (2010). Logística Reversa Aplicada a Resíduos Eletroeletrônicos: Estudo de Caso. VIII Convibra Administração.

Paschoalin Filho, J., Frasson, S., \& Conti, D. (2019). Economia Circular: estudo de casos múltiplos em usinas de reciclagem no manejo de resíduos da construção civil. Desenvolvimento Em Questão, 17(49), 136-157.

Plastivida instituto sócio-ambiental dos plásticos. (2015). Isopor é possível reciclar. Disponível em: http://www.setorreciclagem.com.br/reciclagem-de-isopor/isopor-e-possivel-reciclar/. Acesso em 03 de março de 2019.

Pauli, R. I. P., \& Greco, L. F. (2017). Incentivos governamentais e demanda por empregos verdes nos setores público e privado do Brasil. Revibec-revista iberoamericana de economía ecológica, $36-47$.

Puglisi, M. L., \& Franco, B. (2015). Análise de conteúdo. 2. ed. Brasília: Líber Livro.

Rampazzo, L. (2005). Metodologia cientifica: para alunos de dos cursos de graduação e pósgraduação. 3 ed. São Paulo: Edições Loyola.

Ribeiro, G. P., Costa Silva, L. M., \& Lopes Filho, O. C. (2019). Análise da conversão de multas ambientais em prestação de serviços em prol da preservação ambiental. Revista Gestão \& Sustentabilidade Ambiental, 8(2), 24-46.

Santos, A. M., Oliveira, B. R. B., \& Pimentel, M. S. (2019). Logística reversa e a contabilidade ambiental: um estudo de caso de uma empresa do Grupo Moura. Refas-Revista Fatec Zona Sul, v. 6, n. 2, p. 1-17.

Silva, E. L.; Menezes, E. M. (2005). Metodologia da Pesquisa e Elaboração de Dissertação. 4. ed. Rev. Atual. Florianópolis: UFSC. 
Silva, D. S. D., Rolin, G. O., Maranhão, R. C. D. A., \& Gonçalves, P. A. (2017). Contribuição da logística reversa na responsabilidade social empresarial. Revista Mangaio Acadêmico, 2(1), 5257.

Silva, A. M. G., \& Pimentel, M. S. (2019). Logística reversa na construção civil: um estudo de caso sobre o gerenciamento dos resíduos de construção civil e sua reintegração na cadeia de valor. Refas-Revista Fatec Zona Sul, 6(2), 18-33.

Sistema Nacional De Informações Florestais. (2019). Com destaque para o setor de papel e papelão, mercado de reciclagem movimenta $R \$ 3$ bilhões. Disponível em:

http://www.florestal.gov.br/snif/noticias-do-sfb/mercado-de-reciclagem-do-brasil-movimenta-r\$3-bilhoes-destaque-para-o-setor-de-papel-e-papelao. Acesso em 25 de janeiro de 2019.

Sousa, A. D. L., \& Novais, S. M. (2017). Antecedentes de inovações sustentáveis em Micro e Pequenas Empresas: um estudo de casos múltiplos. Revista de Administração da UEG, 8(2), 27.

Wille, M. M., \& Born, J. C. (2012). Logística reversa: conceitos, legislação e sistema de custeio aplicável. Revista de Administração e Ciências Contábeis, (8).

Yin, R. K. (2015). Estudo de caso: planejamento e métodos. 5. ed. Porto Alegre: Ed. Bookman. 


\title{
Application of reverse logistics: Comparative study in companies from different segments of a municipality in the State of Paraná
}

\begin{abstract}
The study aims to analyze reverse logistics is applied by three companies from different sectors, taking into account the main difficulties and the destination given to recycled materials. For that, a qualitative exploratory research was adopted and a script composed of open questions was applied, characterizing a case study. Through the research, it was possible to identify that the difficulties that organizations face are especially due to the lack of municipal incentives, awareness and sensitization of the community in general. Among the main findings, it was verified the importance of recycling through reverse logistics, since their materials are used for the production of a wide range of items such as ecological tiles, corrugated conduits, ropes, steel rods, plastic wood, packaging for lubricating oil, corrugated ducts, gloves for splicing, in addition to replacing products such as crushed stone in civil construction.
\end{abstract}

Keywords: Reverse logistic; Sustainability; Recycling.

\section{Sobre os Autores}

\section{Cláudio Luiz CHIUSOLI}

Doutor em Administração pela Universidade de São Paulo (FEA/USP).

Professor no curso de Administração da Universidade Estadual do Centro-Oeste (UNICENTRO).

Rua Salvatore Renna, 875 - Santa Cruz, Guarapuava - PR, 85015-430.

E-mail: prof.claudio.unicentro@gmail.com

\section{Josiane POCZYNEK}

Graduada em Administração pela Universidade Estadual do Centro-Oeste (UNICENTRO).

Rua Salvatore Renna, 875 - Santa Cruz, Guarapuava - PR, 85015-430.

E-mail: josianepoczynek@yahoo.com.br.

\section{Silvio Roberto STEFANO}

Doutor em Administração pela Universidade de São Paulo (FEA/USP).

Professor no curso de Administração da Universidade Estadual do Centro-Oeste (UNICENTRO).

Rua Salvatore Renna, 875 - Santa Cruz, Guarapuava - PR, 85015-430.

E-mail: professor-silvio@hotmail.com. 